\title{
Patient Centered Care - A Conceptual Model and Review of the State of the Art
}

\author{
Ravishankar Jayadevappa ${ }^{*}, 1$ and Sumedha Chhatre ${ }^{2}$ \\ ${ }^{I}$ Department of Medicine, Leonard Davis Institute of Health Economic, University of Pennsylvania, 224, Ralston-Penn \\ Center, 3615 Chestnut Street, Philadelphia PA 19104-2676, USA \\ ${ }^{2}$ Department of Psychiatry, 4051, 3535 Market Street, Philadelphia, PA 19104, USA
}

\begin{abstract}
Background: Patient-centered care that encompasses informed decision making can improve treatment choice, quality of care and outcomes. Patient-centered care recognizes the need for major changes in the process of care that arranges health care system around the patient.

Objective: Study objective was to evaluate and discuss the interplay of components of patient- centered care by developing a conceptual model of patient-centered care.

Methods: Comprehensive literature review was conducted using Medline, CINAHL, and Cochrane databases. Included were English language studies addressing issues related to patient-centered-care and patient reported outcomes.

Results: Though the concept of patient-centered care emerged in the early 50s, it exploded in the health care research policy arena exponentially in the late nineties. The conceptual model described here can aid objective and subjective evaluation of patient-centered care. As we strive to improve the quality of care, patient-centered care can play a pivotal role in this process. This however requires changes in our healthcare system so as to improve overall quality of care by minimizing wasteful health resource consumption.

Conclusions: With healthcare costs projected to continue their rapid increase, the current paradigm of healthcare is unsustainable. More research is needed to explore the various attributes of patient-centered care, its acceptability, and comparative effectiveness in the healthcare arena.
\end{abstract}

Keywords: Patient centered care, patient reported outcome, conceptual model, racial and ethnic disparity, policy measures.

\section{INTRODUCTION}

There is growing recognition that patient-centered care is associated with quality of care. Important works that paved the way for the recent emergence of patient-centered care are 'Through the Patient's eyes' edited by Margaret Gerteis et al., and articles by Mead and Bower and by Hobbs [1-3]. The book edited by Gerteis et al. presented the material gathered for the Picker/Commonwealth Program for Patientcentered care that was established in 1987 [1]. Three important themes were addressed: association between patients' interactions with healthcare providers, institutions and systems and their subjective experience of illness and wellbeing; extent to which the systems work to meet patient needs; and incorporation of patients' perspectives on healthcare quality by health care providers, managers, and planners. In their article, Mead and Bower reviewed the conceptual and empirical literature, analyzed five dimensions of patient and doctor relationship in the context of patient centered care and developed a model of the various aspects of the patient-doctor relationship [3]. More recently, Hobbs identified various dimensions of patient-centered care from

*Address correspondence to this author at the Department of Medicine, University of Pennsylvania, 224, 3615 Chestnut Street, Philadelphia PA 19104-2676, USA; Tel: 215-898-3798; Fax: 215-573-8684;

E-mail: jravi@mail.med.upenn.edu the nursing perspective as found in the recent literature [2]. She concluded that the interaction between nurse and patient was central for effective application of patient-centered care. In continuation of these endeavors, in this article we first explore the progression of patient-centered care concept via a comprehensive literature review. We then present our conceptual model of patient-centered care, followed by discussion of the interplay of different constructs for achieving patient-centered care.

Patient-centered care is a concept that has taken off in the past decade or two as the era of health care consumerism has dawned [4]. Since the late 1970s, several health care organizations, policy makers, and regulatory and research agencies have endorsed and embraced the idea of patientcentered care [4. 5]. The Institute of Medicine listed patientcentered care as one the six aims for improvement in its 2001 report 'Crossing the Quality Chasm' and defines patient-centered care as care that respects and responds to the individual patient's preferences, needs and values and ensures that clinical decision incorporates patients' values [6]. Patient-centered care may have important benefits for patients through improved communication, appropriate intervention, enhanced satisfaction and patient reported outcomes, and finally biomedical outcomes $[2-3,7]$. The term patient-centered care is used in many contexts and relations to characteristics of patients and providers. It has been suggested that one of the barriers to the effective 
implementation of patient-centered care is the ambiguity of its definition and key components [2-3]. Patient-centered care implies individualized patient care based on patientspecific information [2, 8] rather than focusing exclusively on the disease [3, 9-12]. This creates a comprehensive healthcare approach, where the physician tries to see the illness through the patient's perspective, and is responsive to the patient's needs and preferences [13].

Patient-centered care is also known as patient-centered approach or patient-focused care $[2,10]$. The concept of patient-centered care includes many subcategories such as patient- centered communication, patient-centered access, patient-centered interview, patient-centered outcome and patient-centered diagnosis [10]. The implementation of patient-centered care has also led to a decrease in the average length of stay, improved patient satisfaction, and efficient and effective treatments, leading to lower costs of care [4, $14,15]$. From the perspective of a provider, via high quality patient-centered care, institutions are able to create a brand name that keeps its old consumers and draws in new ones [4]. Thus, patient-centered care model is being increasingly recognized as important for the delivery of high quality care.

Although many believe that hospitals are oriented to meet the patient's needs, there remain considerable opportunities to enhance their patient-centeredness by treating the patient as a person. To effectively operationalize the patient-centered care, hospitals must aim to facilitate the attributes of patient-centered care through education, shared knowledge, integrated and team management and free flow and accessibility of valued information. This highlights the need for major changes in our healthcare system by addressing or integrating key dogmatic issues such as rising healthcare costs, medical liability, disparity in care and access to care.

\section{METHODS}

\section{Identification of Studies}

A comprehensive search was conducted by the authors to identify studies matching the term 'patient-centered care'. The following electronic databases were searched for English-language articles published in the period 1910 to October 2010: Medline, Pubmed, CINAHL, and Cochrane. Additional studies were obtained via period search updates and from the reference lists of included studies.

\section{Selection Criteria}

Information from abstracts and titles of the studies found via the search was used to include or exclude studies. To be considered for inclusions, studies had to address the issues related to patient-centered care and at least one of key component of patient-centered care such as chronic care, cost, patient reported outcomes, racial and ethnic disparity, provider, preference and utility assessment or policy. Eligible studies also discussed patient reported outcomes in the context of patient-centered care or evaluated the conceptual model of patient-centered care and its components. Studies related to acute care, patient reported outcomes alone and cost were excluded. A flow-chart of study selection process is presented in Fig. (1).

\section{RESULTS}

Our comprehensive review evolved into four main attributes of patient-centered care concept. In this section, we first present the overview of state of the art, followed by a discussion of the four main attributes of patient-centered care and finally present our conceptual model of patient-centered care.

\section{Patient-Centered Care-State of the Art}

The concept of patient-centered care emerged in the early $50 \mathrm{~s}$, and exploded in the health care research policy arena exponentially in the late nineties. In 1990, the PickerCommonwealth program sponsored a book, edited by Gerteis et al., to conceptualize different dimensions of patient-centered care [1]. This important work in the arena of patient-centered care emphasizes quality of care as perceived through patient's perspective. Important dimensions of patient-centered care that were discussed were -respecting patient's individuality, coordination of care that is unique to the environment of hospitals and health care facilities, communications between patients and providers (physician and nurses), intervention strategies for improving quality of patient-centered care within an institution, minimizing physical trauma during acute care, supporting patient's social and emotional needs, role of families, and continuity of care. Another important work in the arena of patient-centered care was a conceptual framework to identify various aspects of doctor-patient relationship encompassed by the concept of patient-centeredness and to assess the advantages and disadvantages of alternative methods of measuring patientcentered care [3]. Patient-centered care was specified through five dimensions-biopsychosocial perspective, the 'patient-as-person', sharing power and responsibility, therapeutic alliance, and the 'doctor-as-person'. The studies that measured (using self-report instruments and external observation methods) these dimensions were reviewed. It was concluded that while some of the measures were able to relate to these dimensions, more research is needed to develop measures for more complex and contextual dimensions of patient-centeredness.

Given the cultural diversity and the noticeable disparities in care between $\mathrm{racial} / \mathrm{ethnic} / \mathrm{minority} /$ poor in our healthcare system, cultural competence needs to be factored into patient-centered care. Some argue that since patient-centered care individualizes care, disparities in care are lessened due to equalization of power between patient and physician, and since patient-centered care fosters positive interactions it should theoretically lower the differential interpersonal behavior [10, 12, 16, 17]. However, if physicians choose to take advantage of the digital age and communicate with their patients primarily via the web, they could magnify disparities for low income and minority patients [10]. Although cultural competence and patient-centered care are two distinct concepts with different goals, (cultural competence sets out to make healthcare equitable for all, whereas patient-centered care sets out to elevate healthcare quality) many of their characteristics overlap. Both concepts: 1) understand and are interested in the patient as a unique person; 2) use a bio-psychosocial model; 3) explore and 


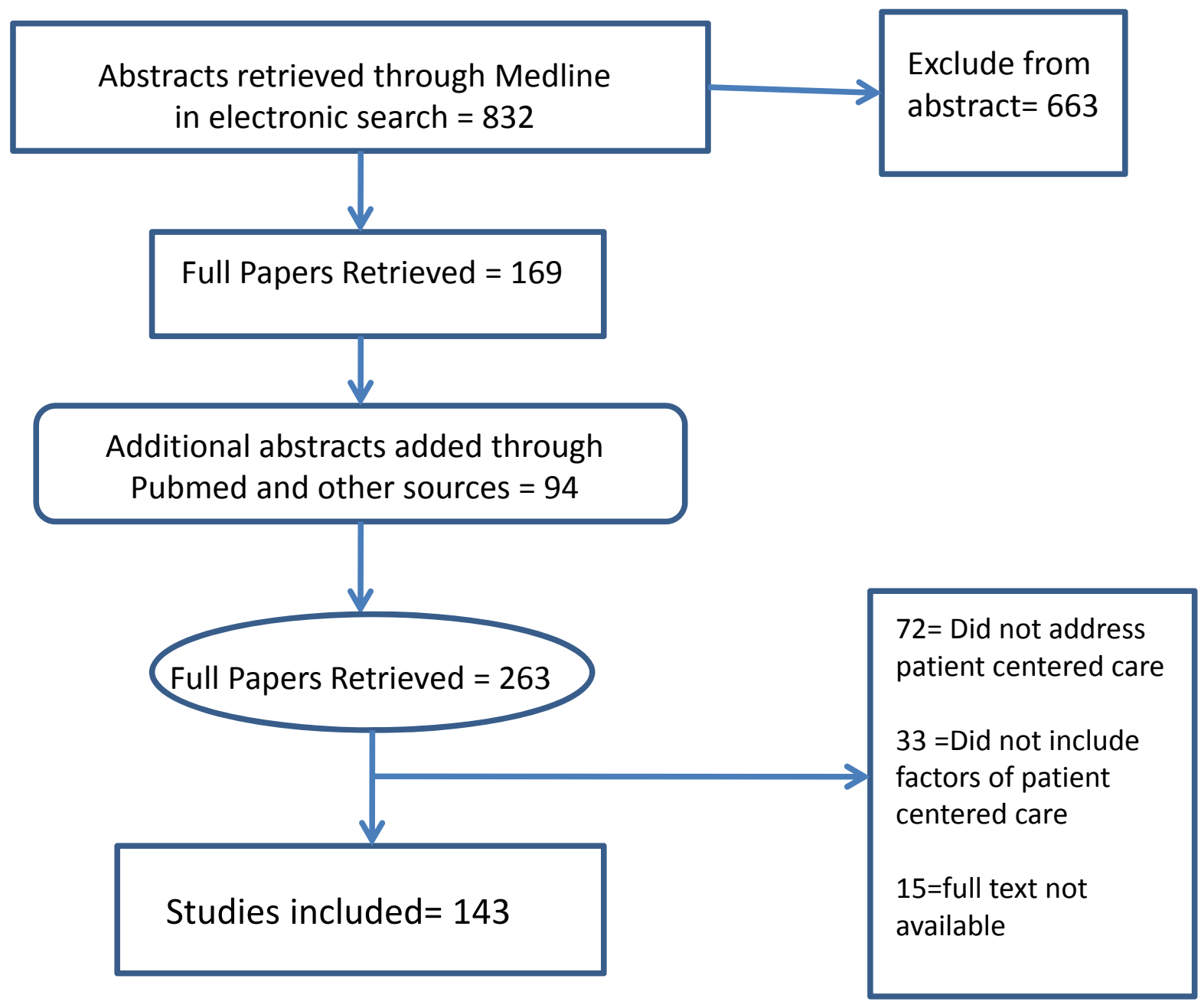

Fig. (1). Results of literature search.

respect patient beliefs, values, meaning of illness, preferences and needs; 3) build rapport and trust; 4) find common ground; 5) are aware of their own biases/assumptions; 6) maintain and are able to convey unconditional positive regard; 7) allow the involvement of friends/family when desired; and, 8) provide information and education tailored to patient's level of understanding.

Saha et al. argue that although cultural competence and patient-centered care are two distinct ideas [10], healthcare providers should seek to incorporate cultural competence into patient-centered care in order to provide healthcare that is both equitable and of high quality. By doing so, providers would seek to include the following attributes of cultural competence: 1) understanding the meaning of culture; 2) knowledge about different cultures; 3) appreciation of diversity; 4) awareness of health disparities and discrimination affecting minority groups; and, 5) effective use of interpreter services when needed. Failure to do so would continue to increase the disparities that are already visible in the healthcare system [1, 9, 10, 12, 13, 16-27]. Silow-Carroll et al. went through an exhaustive literature review and devised a list of eight core components of patient-centered care that are especially pertaining to underserved populations: 1) welcoming environment; 2) respect for patients' values and expressed needs; 3) patient empowerment or "activation"; 4) socio-cultural competence; 5) coordination and integration of care; 6) comfort and support; 7) access and navigation skills; and, 8) community outreach (28). They also identified following key institutional structure and process necessary to build patient centered care policies: 1) feedback and measurement; 2) patient/family measurement; 3) workforce development; 4) leadership; and, 5) involvement in collaborative pilots [28].

Physicians and nurses must acquire certain skills for patient-centered care to be successful. In order for the physician to be able to make an appropriate diagnosis, s/he must be able to identify antecedents, triggers, and mediators of the disease [23]. Thus, physicians must be able to elicit the entirety of the patient's story. This includes not only learning about the sicknesses and symptoms, but also their environment, beliefs, dietary habits, risk factors, and social and psychological function. Through effective patientcentered communication, physicians are able to understand the patient's perspective. This forms a collaborative partnership that actively promotes patient involvement in decision making, ultimately leading to better outcome and satisfaction $[3,5,12,18,21,22,24-26,29]$. In one study, physicians were asked how they would treat a patient with abdominal pain who had already been diagnosed with gastritis by another specialist. Over half choose to put these 
patients on acid lowering therapy, a conventional diagnosis, without inquiring into other triggers such as patient's use of aspirin, alcohol, and tobacco. Ignoring these aspects can potentially decrease the efficacy of treatment [19]. However, eliciting a patient's story requires the physician to have the necessary communication and people skills to build rapport with the patient $[2,5]$. Thus, physicians must spend the necessary time to listen to and understand the patient needs and preferences $[2,5,20]$.

In addition to the physician, another important component in patient-centered care is the nurse. Hobbs outlined the dimensions of patient-centered care from a patient and nurse perspective in the context of acute care [2]. In order for patient-centered care to be effective, it must be able to alleviate the patient's vulnerabilities. Patients willingly seek care because their needs exceed their capacity for self care and patients will experience a heterogeneous response to illness. The nurse must be able to show a caring presence via communication and other manifestations, approach the patient as an individual, have the necessary skills and competencies and be able to deviate from established norms, if necessary. Through this process, the nurse is able to provide effective care, minimize the erosion of individual (patient) identity, address complexity and broaden the explanatory perspectives of illness [2, 30-33]. Hobbs' study reviewed literature between 2000 and 2006 and was primarily focused on patient centered care via a nursing perspective. It rightly pointed out that there is a lack of interdisciplinary discussion and application of patientcentered care [2]. Thus, it is crucial for all components of healthcare systems to incorporate and integrate attributes of patient-centered care. Patient-centered care is highly subjective; its effectiveness is usually measured through patient reported surveys [5, 34]. Patients were more likely to view a visit as patient centered if it included a discussion of the problem as well as discussion and agreement about treatment options [2-6, 8-10, 13, 35]. A study by Wolf et al. indicated no significant differences in the level of satisfaction between patients receiving patient-centered care and those not. However, they did find that nurses who used patient-centered care were able to positively influence presurgery preparations and help patients fill discharge prescriptions [27]. Overall, physicians and nurses must also determine when, how and which type of attributes of patientcentered care is most appropriate to use. However, there exists a dearth of research in identifying diseased specific decision aids and establishing their comparative effectiveness in understanding patients' need and preferences and tailoring appropriate interventions.

\section{Patient Centered Care - Clinical Convenience}

Studies have shown that by practicing patient-centered care, facilities experience improvement in patients' health status, quality of care and increased efficiency of care [32, 36-67]. One study found that if patients considered their visit to be patient-centered then their recovery improved, diagnostic tests and referrals were 50 percent less frequent and number of subsequent visits decreased [32]. Another study found that patients wanted to be treated with a patientcentered approach [50]. Doing so meant that the patients were more likely to be satisfied, more enabled and showed signs or symptoms of improvement [32, 47, 50, 65, 68, 69].
It was also found that a perceived patient-centered care visit led to fewer subsequent visits [32]. Finally, an excellent patient-physician rapport as well as continuity of care was correlated with improved preventive care delivery [60]. Two aspects of patient-centered care, effective communication and continuity of care, are especially important [45].

A review by Stewart showed that effective physicianpatient communication positively affects the patients' emotional health and leads to symptom resolution, functional and physiologic status and pain control [70]. Other studies also found that a physician finding a common ground with their patient was more likely to affect outcomes than simply talking about the illness [32, 36, 37, 39-44, 46, 49, 54-60, $62-64,69]$. In fact, agreeing with the patient about treatment options and follow up were strongly related to the patient's recovery [44]. However, another review, which looked at interventions in patient center communication, came to the conclusion that changes in behavior, perceptions, and health behavior outcomes commonly occur but changes in health status and utilization are rare $[40,71]$. While these studies discuss the complexities of medical interaction, the importance attached to the issue of sensitivity depends, in part, on the intended function and outcome measure. Thus, a combined biological, psychological, social and economic perspective is crucial to account for the full range of problems presented in care process.

Continuity of care has led to improved outcomes of diabetes care, delivery of preventive care and clinical satisfaction while also decreasing the number of hospitalizations, emergency department visits, readmissions, and reducing length of stay [5, 62, 63, 69]. However, disparities in care can decrease the continuity in care and the effectiveness of patient physician communication, putting certain racial and ethnic groups at a greater disadvantage. One study noted that time spent with the patient may not be the cause of disparities [16]. Instead, they suggest that patient engagement and participation are main factors [16]. It was also found that the decision to press malpractice suits was associated with a perceived lack of patient centeredness and its components [20, 63]. Another study, however, disagrees with the cost savings assessment. Instead, it reports that patient centered care improves patients' health outcomes at a higher cost [38]. Integrating cost aspects of care and establishing comparative effectiveness of patient centered care activities may aid effective integration of patient centered care into conventional health care systems.

Patient centered access is one way to decrease cost and increase clinical utility. Access can be increased through group visits, office appointments with non-physician providers, telephone appointments, and online communication [48, 72]. Group visits improve efficiency and encourage and elicit greater adherence and satisfaction, improved health outcomes and fewer hospitalizations [39, $42,51,60,61,64,72,73]$. If implemented when physical examination is needless, telephone appointments can decrease the frequency of office visits and costs while maintaining patient satisfaction and outcomes [48]. Telephone appointments have already been implemented effectively for medical conditions such as depression, asthma, and urinary tract infections [36, 46, 55, 58, 62]. The widespread availability of the internet has changed the 
modes and methods of communication. It has been reported that majority of patients with email access wanted to communicate with their physicians via the internet, and more than a third were willing to pay for this service [36, 37, 40, $41,43,44,46,49,54-58,62,63,74]$. However, the implementation of these services has been slow due to physician concerns about reimbursement and other financial and privacy concerns [37]. The Veteran's Affairs has implemented a patient centered care methodology for their patients suffering from chronic diseases and old age and found it to be more cost effective than institutional care. They also found that it "preserve[s] functional independence and postpone or even obviate[s] the need for institutional care for many who are frail from chronic illness or advanced age" [54]. Another problem with our system is the lack of timely appointments which inflict additional cost and inefficiency [52]. By following an advanced care system, where approximately 50 percent of the workday's appointment slots are kept open, patients can schedule appointments according to their own needs [52]. This model was implemented in a Chicago primary care network and showed a significant improvement in timeliness of visits, patient satisfaction, and continuity of care [53].

\section{Patient Centered Care- Patient Reported Outcomes}

Patient reported outcomes, such as health related quality of life, satisfaction with care, trust, psychological well-being and utility of preferences have the potential to play a key role in bringing the patient's voice to the patient-centered care $[59,75]$. A study by Stewart et al. showed that if the patient perceived the visit to be patient-centered, it was associated with positive outcomes [32]. Studies have reported that patient-centered care can enhance patient satisfaction and outcomes [3, 76-86]. Flocke et al. discovered that patientcentered care style was associated with higher patientreported quality of primary care and satisfaction with care [46]. The Veteran Affairs ran a pilot patient-centered care program in Florida and found improved patient satisfaction, as well as physical and mental health functional status [41]. A study of headache found that if patients felt that a full discussion of their problem took place, their headache issues were likely to be resolved after one year [74]. Few studies have directly looked into the relationship between patientcentered care and patient reported outcomes, but it is reasonable to say that patient-centered care leads to improved outcomes.

In harmony with patient reported outcomes, informed decision making is at the core of patient-centered care model, which is a process that implies that the physician's knowledge is transferred to the patient, who then has the knowledge and preferences necessary to make a decision. This movement toward informed decision making has created a need for an explicit assessment of patient preferences for treatment. Preference (or utility) is defined as levels of satisfaction, distress or desirability that people associate with particular health state. Along with clinical guidelines, patient preferences provide direction for treatment selection. Patient preferences also help inform clinical decisions where science has yet to provide dominant solutions to healthcare problems. A patient's belief, attitude and importantly values that may influence his preferences_for outcomes and risk of treatments, are vital for effective patient-physician communication [5, 87-94]. Broadly, the methods to assess the preferences fall into either revealed preference or stated preference. Revealed preference methods are based on observed data relating to individuals' actual behavior. This method involves inferring values through related conditions (or markets), and thus relying on revealed preferences (example: hedonic pricing and travel cost models). In the revealed preference, individuals choose to discern the best possible option on the basis of their behavior. The stated preference relies on structured or hypothetical conditions (example: contingent valuation methods and choice experiments). Stated-preference methods use surveys/questions to elicit patients' preferences for hypothetical options in an experimental framework. Thus, one of the key dimensions of patient centered care that stresses in identifying patient-as-person depends on understanding the illness from a patient's perspective via patient reported outcomes and by incorporating shared responsibility, patient's need and preferences in clinical decision making. However, we know very little about how these issues integrate into the dimensions of patients centered care. Thus, future research may ameliorate some of these issues that are stalemating patient-centered care.

\section{Patient Centered Care - Disparity in Care}

The factors contributing to health care disparities are race and ethnicity and socioeconomic status. It has long been thought that patient-centered care can aid in reducing race and ethnic disparities in quality of health care [17]. Race concordant visits tend to have more patient-centered care components. Race discordant visits led to lower patient reported mutual understanding, satisfaction with communication, compliance, and greater patient reported problems with the physician and less positive physician affect [95-98]. Minorities considering therapies may be less informed about and less involved in treatment choice. Several patient centered care factors are involved in the physician-patient relationship and may aid in enhancing patient participation in clinical decision making process. Trust has been found to be a key determinant in patient continuity and so has been adherence to treatment $[32,95-$ 105]. One study observed that racial and ethnic minorities have less positive perceptions of their physicians than whites [96]. This is not surprising given that the quality of patientphysician interactions is poorer among non-white patients [10]. One way to bridge this gap is to facilitate raceconcordant visits. Lower levels of trust, satisfaction in care, and participation in medical decisions have characterized race-discordant visits [95-98]. The 2001 Health Care Quality Survey of the Commonwealth Fund found that African Americans, Hispanics, and other minorities reported higher rates of difficulties in communicating with their physician than their white counterparts [106]. In addition, African Americans were twice as likely to be treated disrespectfully [106]. This is especially disturbing since respectful treatment is a strongest predictor of overall satisfaction with care $[10$, 68, 107, 108]. In another study, African American patients' visits showed a less positive effect [109] which is linked with patient satisfaction, adherence, and return visits [21]. However, the study by Saha et al. reported that not all racial disparities in healthcare were attributable to the difference in patient-physician relationship [10]. 
Patient centered communication has been shown to influence the recall of information, treatment adherence, and satisfaction with care and health outcomes [21, 70, 109-113]. In a study by Johnson et al., physicians were found to be more verbally dominant, and therefore less 'patient centered' when dealing with African American patients [109]. Cooper's study found that race-concordant visits were longer [97], which also helps increase patient's trust of their physician [107]. Race concordant visits are more participatory. This is important, since participatory decision making is strongly correlated with patient satisfaction [98]. Research has shown that discordant relationships are characterized by lower patient reported mutual understanding, satisfaction with communication, compliance, and greater patient reported problems with the physician and less positive physician effect $[73,95-98,106]$.

Language concordance is also an important part of patient centered communication. In the US, there are approximately nineteen -million people who have a limited proficiency in English, Studies have shown that language discordance harms healthcare process and lowers the patients' ratings of care [113-125]. In a study involving Hispanic patients, it was discovered that those proficient in English were more likely to have medication side effects explained to them and have a higher patient satisfaction rating [117]. It is also interesting to note that those patients who spoke limited English were more likely to have a mammogram within the following two years suggesting that test ordering may substitute communication [121]. This disparity is significant since it adds an avoidable cost to our already strained healthcare system. In Latino asthma patients, language concordance positively affected appointment-keeping and medication adherence [123]. One way to potentially solve the language discordance problem and potentially reduce some of the disparities in care is to provide interpreters. Studies have found that the use of professional interpreters decreases disparities in services received and increases the delivery of health care [122]. Interestingly enough, a study found that patient satisfaction increased and errors decreased with the use of remotesimultaneous interpretation rather than proximateconsecutive interpretation (interpreter physically present) [120].

Minority groups, especially Asians, report lower levels of cultural sensitivity among physicians which affects the quality of patient-physician interaction [102]. Other factors that may influence patient-centered care are unconscious racial and ethnic biases which inadvertently lead to changes in the physician's interpretation of symptoms, interpersonal behavior [103], and patient health literacy [10]. However, a study found that if medical students are taught with a patientcentered attitude, quality of care for African American patients is improved [99]. Many believe that patient-centered care reduces disparities of care across the spectrum [17] since it treats each person as a "unique human being" [32] and equalizes power between the physician and the patient [96]. In recent studies, it has been shown that physicians are unprepared to provide culturally competent care. This indicates the need to increase cultural competency training $[112,114-116,118,119,126,127]$. However, as these authors note, we must avoid making sweeping generalizations [28].

\section{Patient-Centered Care - Health Care System}

The Patient Protection and Affordable Care act (HR 3590) provides a much needed focus and opportunity for an expanded continuum of biomedical research to patient-centered outcomes. Establishment of a patientcentered outcomes research institute through this act was charged with prioritizing and promoting research that emphasizes the generation of relevant, high-quality evidence to help physicians and patients make informed decisions about the patient's healthcare, assist healthcare delivery systems in providing evidence-based, efficient, and safe healthcare, ensure that evidence is obtained from ethnically diverse and geographically dispersed communities, and develop broad prevention and screening strategies that promote health across diverse populations.

Many experts believe that our current healthcare system is broken because it is based on patient helplessness [28]. Although most people believe hospitals are oriented to meet the patient's needs, there are considerable opportunities to make them more patient-focused and not focused on the doctor, the nurse or the other healthcare providers. A patientcentered healthcare system will need to involve improvements in the measures of hospital and physician performance, teaching communication skills to patients and providers, the development of patient-centered care practice guidelines and payment options [28, 128-130]. These efforts must take place at four levels: organizational, patient, provider, and community.

In a 2020 vision of patient-centered primary care, Davis lists seven essential components: superb access to care; patient engagement in care; clinical information systems that support high quality care, practice-based learning, and quality improvement; care coordination; integrated, comprehensive care and smooth information transfer across a fixed or virtual team of providers; ongoing, routine patient feedback to practice; and publicly available information [74]. Denmark has already begun implementing a patient-centered approach which has been successful. The physicians are paid via per patient panel fee and fee-for-service, which allows physicians provide open access care. Denmark's system implements an electronic prescribing system as well as "off hours" telephone service operated by physicians [43]. In addition to Denmark, the Veteran Affairs has also begun implementing patient-centered care components into their system using a telephone service to inquire into the patient's status and compliance [54, 131]. As policy makers move toward patient-centered care approach to enhance quality of care, healthcare institutions should be prepared to integrate their care activities in and around patient focused approached activities by adopting appropriate information technology, enhancing communications and providing decision aid tools [72, 84, 128, 132-137].

\section{Patient-Centered Care - Conceptual Model}

The existing research reviewed in the above sections presents multiple dimensions and various contexts for patient-centered care. The concept and basic tenets of patient-centered care have been embraced by the policy makers and leaders in the healthcare arena. However, operationalization of this philosophy is hampered due to the lack of conceptual clarity for researcher, clinical practice and 
policy makers in understanding how these different dimensions will have an impact on improved outcomes and resource utilization. Additionally, the patient-centered care requires an unanticipated level of commitment and significant adjustments in organization structures, physician role and patients belief. Thus, a concise model needs to be developed in order to facilitate implementation of patientcentered care. As observed from Fig. (2), the conceptual model of patient-centered care consists of multiple domains (e.g., patient demographics and clinical characteristics, hospital, nurse and physician attributes) that influence treatment choice, process of care and outcomes. Patientcentered care encompasses informed decision making and is a particular process of decision making by patient and physician where the patient: 1) understands the risk or seriousness of the disease or condition to be prevented; 2) understands the preventive service, including the risks, benefits, alternatives and uncertainties; 3) has weighted his or her values regarding the potential benefits and harms associated with treatment; and 4) has engaged in decision making at a level that he or she desires and feels comfortable $[2-6,8,10]$. Patients differ, across age and ethnicity, in the extent to which they wish to be involved in decision making for their medical care and treatment [10]. Although some patients prefer to actively participate in decision making, others opt for a more passive role and defer decisions to their physicians. Physicians and nurses are thus encouraged to tailor the medical care per the preferences of patients $[2-6,8$ $10,12,13]$. Since patients' decision about healthcare utilization may be influenced by their tastes and preferences, it is important to have a better understanding of these preferences. Respecting the patient's needs and preferences and improving the trust between patient and their caregiver is one of the key attributes of patient-centered care.

\section{DISCUSSION}

This systematic review identified 143 studies of patientcentered care. The findings from this literature review indicate that, patient-centered care model has many promising attributes for improving quality of care, reducing cost and improved satisfaction with care. However, it's wide spread acceptability has been hampered due to lack of leadership and effective integration into policy measures. The challenge lies in strengthening the attributes of patient centered care through macro level policy measures and micro level incentives at organization and system level to adopt the activities related to patient-centered care. Patientcentered care revolves around the issues of patient's role in his or her own healthcare. Patients have ethical values and legal mandate that allows them to make informed decisions regarding their healthcare. Thus, physicians must facilitate the process of informed decision making and tailor the treatment(s) to match patient preferences (or needs) [32, 138143].

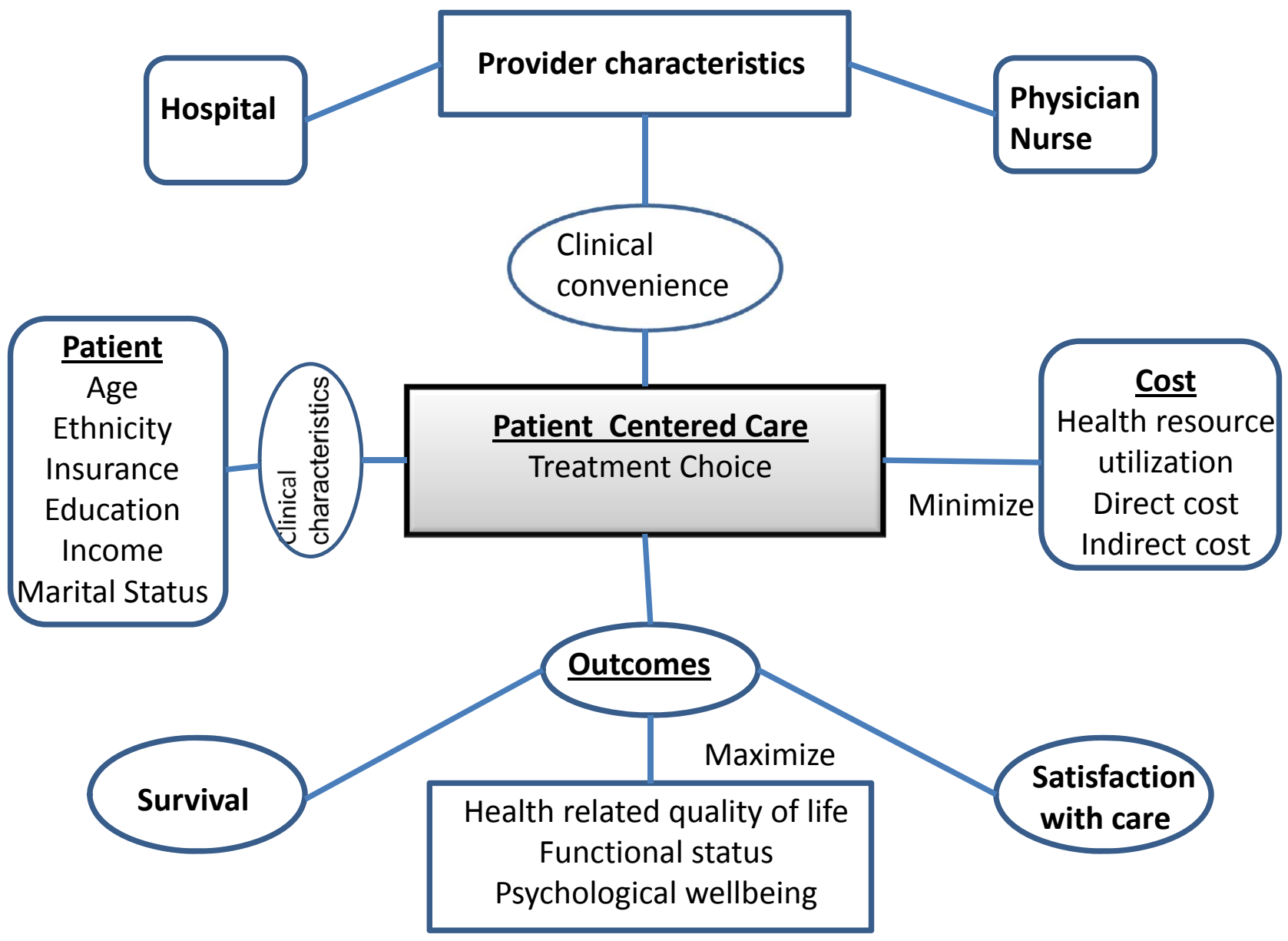

Fig. (2). Conceptual model of patient centered care. 
The patient-centered care model in healthcare should integrate patient preferences, needs and wants, engage patients in clinical decision making and tailor the treatment to maximize outcomes in a cost effective way. This relatively old concept provides unique challenges and opportunities for its application to the ever changing arena of healthcare [32, 59, 138-142]. Such decision making demands integrating the best medical knowledge into patient care, supporting more active patient participation in care and promoting systems of care that are responsive to the patient's needs or preference. Thus, patient-centered care model integrates (1) understanding the patient and the illness, (2) arriving at mutual understanding regarding illness management and therapeutic alliance, (3) providing valued information, (4) enhancing hospital, doctor and patient relationship; and (5) sensitivity about resource allocation and cost.

Many have advocated in favor of adopting patientcentered care to alleviate racial and ethnic disparity in quality of care. Review of interaction between cultural competence and patient centeredness revealed that although the two concepts have had different histories and foci, many of their core features are the same $[3,10,68,95-98,100$, $106,108]$. Each approach holds a promise for improving the quality of healthcare for individual patients, communities and populations [10]. Though there is a widespread interest to adopt patient-centered care to improve quality of care, there is no consensus yet on how best to measure and report patient- centered care. It is crucial that such measures reflect the main components of patient-centered decision quality. This ensures that the patients have adequate knowledge and understanding of the decision to be made and the choices presented, establish trust in shared information and decision, and the treatment decision reflect the patient's desire for involvement in decision making and his/her values and preference. Measurement of patient reported outcomes, such as generic and disease specific health related quality of life instruments are being used increasingly to measure outcomes that are important to patients with reasonable accuracy [32]. In addition, development of valid and practical measures of decision quality would allow for documentation of poor decision making process and lead to further development and dissemination of effective interventions designed to promote superior quality decision making [32, 138-142]. Measuring decision quality and process of care outcome allows patients, physicians, and other interested stakeholders to evaluate the patient centeredness of the overall care $[2-6,8-10,13]$.

\section{LIMITATIONS}

The search strategy, its review of English-language only articles, and publication bias may have limited this systematic review. To limit the effect of these potential biases, the search strategy was developed and independently reviewed using Medline and Pubmed by the authors, and articles that were known to the authors previously were included in the review.

\section{CONCLUSIONS}

The patient-centered care model that integrates mutually beneficial partnerships among healthcare providers, patients and families has profound implications for the planning, delivery, and evaluation of care. Patient-centered care and evidence based care are not mutually exclusive. Instead, both hold tremendous potential for complementarities in healthcare and should be used to enhance clinical relationships in which caring is humble, mindful, nuanced and comparatively effective. More importantly, at the core the patient-centered care is the quality of interactions between patients and care providers. Thus, the value of information plays a crucial role in patient centered and evidence based practices. Developing decision quality measures and educating both health professionals and patients regarding process of decision making is crucial for effective integration of patient-centered care.

As we strive to improve quality of patient care, patientcentered care can play a central role in this effort. However, this requires changes in our healthcare system from reimbursement process to discharge planning and social environment [7]. Enhancing decision quality may require systematic changes in the healthcare system that can lead to incorporation of shared decision making interventions into routine care and realignment of financial incentive to reward providers who foster and support high-quality patient centered decision making. Our current reimbursement system should be rewarded through incentive, rather than penalizing for choosing less aggressive care. It should also value the kind of physician-patient interactions that can lead to more patient-centered care. This may lead to improved overall quality of care by minimizing wasteful health resource consumption that have little or no benefit to the patient. With healthcare costs projected to continue their rapid increase, the current paradigm of healthcare is unsustainable, and can benefit from patient-centered care. Patient-centered care can play a vital role in healthcare policy, allocation of resources and delivering appropriate care by effectively integrating patient and provider perspective. The appeal of this unique concept is global. However, extensive research is necessary to demonstrate assessment, analytical methods and evaluation of patientcentered care for its effective integration into our healthcare setting.

\section{ACKNOWLEDGEMENT}

The authors would like to thank Suman Sajjan for excellent support as a research assistant.

\section{REFERENCES}

[1] Gerteis M, Edgman-Levitan S, Daley J, et al. Through the patient's eyes: understanding and promoting patient-centered care. San Francisco, CA: Jossey-Bass 1993.

[2] Hobbs JL. A dimensional analysis of patient-centered care. Nurs Res 2009; 58(1): 52-62.

[3] Mead N, Bower P. Patient-centeredness: a conceptual framework and review of the empirical literature. Soc Sci Med 2000; 51: 1087110 .

[4] Charmel PA, Susan BF. Building the business case for patientcentered care. Healthc Financ Manage 2008; 62(3): 80-5.

[5] Robinson JH, Callister LC, Berry JA, Dearing KA. Patient-centered care and adherence: definitions and applications to improve outcomes. J Am Acad Nurse Pract 2008; 20(12): 600-7.

[6] Institute of Medicine. Crossing the quality chasm: a new health system for the 21 st century. Washington, DC: National Academy Press 2001.

[7] Epstein RM, Fiscella K, Lesser CS, Stange KC. Why the nation needs a policy push on patient-centered health care. Health Affairs 2010; 29(8): 1489-95.

[8] Leino A. Planning patient-centered care. Am J Nurs 1952; 52(3): 324-5. 
[9] Levenstein JH, McCracken EC, McWhinney IR, et al. The patientcentered clinical method-A model for the doctor-patient interaction in family medicine. Fam Pract 1986; 3: 24-30.

[10] Saha S, Mary CB, Cooper LA. Patient centeredness, cultural competence and healthcare quality. J Natl Med Assoc 2008; 100(11): 1275-85.

[11] Berwick DM. What 'patient-centered' shouldmean: confessions of an extremist. Health Affairs 2009; 28(4): w555-w65.

[12] Pelzang R. Time to learn: understanding patient-centered care. Br J Nurs 2010; 19(4): 912-7.

[13] McWhinney I. The need for a transformed clinical method. In: Stewart M, Roter D, Eds. London: Sage 1989.

[14] Meterko M, Wright S, Lin H, Lowy E, Cleary PD. Mortality among patients with acute myocardial infarction: the influences of patientcentered care and evidence-based medicine. Health Serv Res 2010; 45(5): 1188-204.

[15] Na'poles AM, Gregorich SE, Santoyo-Olsson J, O'Brien H, Stewart AL. Interpersonal processes of care and patient satisfaction: do associations differ by race, ethnicity, and language? HSR: Health Serv Res 2009; 44(4): 1326-43.

[16] Johnson RL, Saha S, Arbelaez JJ, et al. Racial and ethnic differences in patient perceptions of bias and cultural competence in health care. J Gen Intern Med 2004; 19: 101-10.

[17] Van Ryn M. Research on the provider contribution to race/ethnicity disparities in medical care. Med Care 2002; 40(Suppl 1): 1140-51.

[18] Ades PA, Waldmann ML, McCann WJ, Weaver SO. Predictors of cardiac rehabilitation participation in older coronary patients. Arch Intern Med 1992; 152: 1033-5.

[19] Avorn J, Everitt DE, Baker MW. The neglected medical history and therapeutic choices for abdominal pain: a nationwide study of 799 physicians and nurses. Arch Intern Med. 1991; 151: 694-8.

[20] Beckman DB, Frankel RM. The effect of physician behavior on the collection of data. Ann Intern Med 1984; 101: 692-6.

[21] Hall JA, Roter DL, Katz NR. Meta-analysis of correlates of provider behavior in medical encounters. Med Care 1988; 28: 65775.

[22] Kaplan SH, Greenfield S, Ware JE Jr. Assessing the effects of physician-patient interactions on the outcomes of chronic disease. Med Care 1989; 27(Suppl 3): S110-S27.

[23] Leo G. Patient-centered care: antecedents, triggers, and mediators. Altern Ther Health Med 2006; 12(4): 62-70.

[24] Lorig KR, Mazonson PD, Holman HR. Evidence suggesting that health education for self-management in patients with chronic arthritis has sustained health benefits while reducing health care costs. Arthritis Rheum 1993; 36: 439-46.

[25] Mullen PD. Efficacy of psychoeducational interventions on pain, depression and disability in people with arthritis: a meta-analysis. J Rheumatol 1987; 14(Suppl 15): 33-9.

[26] Wilson SR, Scamagas P, German DF, et al. A controlled trial of self-management education for adults with asthma. Am J Med 1993; 94: 564-76

[27] Wolf D, Lehman L, Quinlin R, et al. Can nurses impact patient outcomes using a patient-centered care model? J Nurs Admin 2008; 38(12): 9 .

[28] Silow-Carroll S, Alteras T, Stepnick L. Patient-centered care for underserved populations: definition and best practice. Washington, DC: Economic and Social Research Institute 2006.

[29] Levinson W, Lesser CS, Epstein RM. developing physician communication skills for patient-centered care. Health Affairs 2010; 29(7): 1310-8

[30] Levine ME. This I believe about patient centered care. Nurs Outlook 1967; 15(7): 53-5.

[31] Elison D. Patient-centered care in operating room. Nurs Clin North Am 1968; 3(4): 631-9.

[32] Balint E. The possibilities of patient-centered medicine. J R Coll Gen Pract 1969; 17: 269-76.

[33] Woody M, Mallison M. The problem-oriented system for patient centered care. Am J Nurs 1973; 73(7): 1168-75.

[34] Edvardsson D, Innes A. Measuring person-centered care: a critical comparative review of published tools. Gerontologist 2010: 1-13.

[35] Little P, Everitt H, Williamson I, et al. Preferences of patients for patient centred approach to consultation in primary care: observational study. Br Med J 2001; 322(7284): 468-72.

[36] Barry HC, Hickner J, Ebell MH, Ettenhofer T. A randomized controlled trial of telephone management of suspected urinary tract infections in women. J Fam Pract 2001; 50: 589-94.
[37] Bauchner H, Adams W, Burstin H. "You've got mail": issues in communicating with patients and their families by e-mail. Pediatrics 2002; 109: 954-6.

[38] Bechel DL, Myers WAA, Smith DGG. Does patient-centered care pay off? Jt Comm J Qual Improv 2000; 26(7): 400-9.

[39] Beck A, Scott J, Williams P, et al. A randomized trial of group outpatient visits for chronically ill older HMO members: the cooperative health care clinic. J Am Geriatric Soc 1997; 45: 543-9.

[40] Beckman H, Markakis BKM, Suchman AL, Frankel RM. The doctor-patient relationship and malpractice: lessons from plaintiff depositions. Arch Intern Med 1994; 154(12): 1164-8.

[41] Bensing JM, Sluijis EM. Evaluation of an interview training course for general practitioners. Soc Sci Med 1985; 20: 737-44.

[42] Coleman EA, Eilertsen TB, Kramer AM, et al. Reducing emergency visits in older adults with chronic illness. A randomized, controlled trial of group visits. Eff Clin Pract 2001; 4: 49-57.

[43] Davis K. The Danish health system through an American lens. Health Policy 2002; 59: 119-32.

[44] Epstein RM, Franks P, Fiscella K, et al. Measuring patient-centered communication in patient-physician consultations: theoretical and practical issues. Soc Sci Med 2005; 61(7): 1516-28.

[45] Flach SD, McCoy KD, Vaughn TE, et al. Does patient-centered care improve provision of preventive services? J Gen Intern Med 2004; 19(10): 1019-26.

[46] Flocke SA, Miller WL, Crabtree BF. Relationships between physician practice style, patient satisfaction, and attributes of primary care. J Fam Pract 2002; 51(10): 835-40.

[47] Greenfield S, Kaplan SH, Ware JE Jr, et al. Patients' participation in medical care: effects on blood sugar control and quality of life in diabetes. J Gen Intern Med 1988; 3: 448-57

[48] Leonard BL, Seiders K, Wilder SS. Innovations in access to care: patient-centered approach. Ann Intern Med 2003;139(7): 568-74.

[49] Lewin SA, Skea ZC, Entwistle V, et al. Interventions for providers to promote a patient-centered approach in clinical consultations. Update Software: Oxford 2001; vol. 4.

[50] Little P, Everitt H, Williamson I, et al. Observational study of effect of patient centeredness and positive approach on outcomes of general practice consultations. Br Med J 2001; 323(7318): 908-11.

[51] Masley S, Phillips S, Copeland JR. Group office visits change dietary habits of patients with coronary artery disease-the dietary intervention and evaluation trial (D.I.E.T.). J Fam Pract 2001; 50: 235-9.

[52] Murray M, Berwick DM. Advanced access: reducing waiting and delays in primary care. JAMA 2003; 289: 1035-40.

[53] Murray M, Bodenheimer T, Rittenhouse D, Grumbach K Improving timely access to primary care: case studies of the advanced access model. JAMA 2003; 289: 1042-6.

[54] Perlin JB, Kolodner R, Roswell RH. The veterans health administration: quality, value, accountability, and information as transforming strategies for patient centered care. Am J Manage Care 2004; 10(11): 828-36.

[55] Pinnock H, Bawden R, Proctor S, et al. Accessibility, acceptability, and effectiveness in primary care of routine telephone review of asthma: pragmatic, randomised controlled trial. BMJ 2003; 326 : 477-9.

[56] Riccardi VM, Kurtz SM. Communication and counseling in health care. Springfield, Ill: Charles C. Thomas 1983.

[57] Ryan P, Kobb R, Hilsen P. Making the right connection: matching patients to technology. Telemed J e-Health 2003; 9(1): 81-8.

[58] Simon GE, VonKorff M, Rutter C, Wagner E. Randomised trial of monitoring, feedback, and management of care by telephone to improve treatment of depression in primary care. BMJ 2000;320: 550-4.

[59] Stewart M, Brown J, Donner A, et al. The impact of patientcentered care on outcomes. J Fam Pract 2000; 49(9): 796-804.

[60] Trento M, Passera P, Tomalino M, et al. Group visits improve metabolic control in type 2 diabetes: a 2-year follow-up. Diabetes Care 2001; 24: 995-1000.

[61] Wagner EH, Grothaus LC, Sandhu N, et al. Chronic care clinics for diabetes in primary care: a system-wide randomized trial. Diabetes Care 2001; 24: 695-700.

[62] Wasson J, Gaudette C, Whaley F, et al. Telephone care as a substitute for routine clinic follow-up. JAMA 1992; 267: 1788-93. 
[63] Wasson JH, Sauvigne AE, Mogielnicki RP, et al. Continuity of outpatient medical care in elderly men: a randomized trial. JAMA 1984; 252: 2413-7.

[64] Weinger K. Group medical appointments in diabetes care: Is there a future? Diabetes Spectrum 2003; 16: 104-7.

[65] Williams GC, Freedman ZR, Deci EL. Supporting autonomy to motivate patients with diabetes for glucose control. Diabetes Care 1998; 21: 1644-51.

[66] Davis K, Stremikis K. Family medicine: preparing for a highperformance health care system. J Am Board Fam Med 2010; 23(Suppl): S11-S16.

[67] Stewart M, Brown JB, Weston WW, McWhinney IR, McWilliam CL, Freeman TR. Patient-centered medicine: transforming the clinical methods. In: Stewart M, Brown JB, Freeman TR, Eds. Abingdon, Oxon, UK: Radcliffe Medical Press Ltd 2006

[68] Kaplan SH, Greenfield S, Gandek B, et al. Characteristics of physicians with participatory decision-making styles. Ann Intern Med 1996; 124: 497-504

[69] Serrano-Gil M, Jacob S. Engaging and empowering patients to manage their type 2 diabetes, Part I: a knowledge, attitude, and practice gap? Adv Ther 2010; 27(6): 321-33.

[70] Stewart MA. Effective physician-patient communication and health outcomes: a review. CMAJ 1995; 152: 1423-33.

[71] Weiner M, Biondich P. The influence of information technology on patient-physician realtionship. J Gen Intern Med 2006; 21(1): S35S39

[72] Breen GM, Wan TT, Zhang NJ, Marathe SS, Seblega BK, Paek SC. Improving doctor-patient communication: examining innovative modalities vis-a-vis effective patient-centeric care management technology. J Med Syst 2009; 33(2): 155-62.

[73] Tew J, Klaus J, Oslin DW. The behavioral healht laboratory: building a stronger foundation for the patient-centered medical home. Fam Syst Health 2010; 28(2): 130-45.

[74] Davis KA. 2020 vision of patient-centered primary care. J General Intern Med 2005; 20(10): 953

[75] Curtis JR. The "patient-centered" outcomes of critical care: what are they and how should they be used? New Horiz 1998; 6(1): 2632 .

[76] Morris M. Patient-centered outcomes after therapy for colorectal cancer. Surg Oncol Clin N Am 2006; 15(1): 195-211.

[77] Wagner EH, Bennett SM, Austin BT, Green SM, Schafer JK, VonKorff M. Finding common ground: patient-centerdness and evidence-based chronicc illness care. J Altern Complement Med 2005; 11(1): S7-15.

[78] McHorney CA. Ten recommendations for advancing patientcentered outcomes measurement for older persons. Ann Intern Med 2003; 139(5 pt 2): 403-9.

[79] Michie S, Milles J, Weinman J. Patient-centerdness in chronic illness: what is it and does it matter? Patient Educ Couns 2003; 51(3): 197-203.

[80] McCormack B. A conceptual framework for person-centered practice with older people. Int J Nurs Pract 2003; 9(3): 202-9.

[81] Mead N, Bower P. Patient-centered consultations and outcomes in primary care: a review of the literature. Patient Educ Couns 2002; 48(1): 51-61.

[82] Brown BJ, Stewart M, McWilliam CL. Using the patient centered methods to achieve excellence in care for women with breast cancer. Patient Educ Couns 1999; 38(2): 121-9.

[83] Brown SJ. Patient-centered communication. Annu Rev Nurs Res 1999; 17: 85-104

[84] Lutz BJ, Bowers BJ. Patient-centered care: understanding its interpretation and implementation in health care. Sch Inq Nurs Pract 2000; 14(2): 165-83.

[85] Chewing B, Sleath B. Medication decision-making and management: a client-centered model. Soc Sci Med 1996; 42(3): 389-98.

[86] Wagner EH, Austin BT, VonKorff M. Organizing care for patient with chronic illness. Milbank Q 1996; 74(4): 511-44.

[87] Buetow S, Getz L, Adams P. Individualized population care: linking personal care to population care in general practice. Eval Clin Pract 2008; 14(5): 761-6.

[88] Dolan JG. Shared decision-making-transfering research into practice: the analytic hierarchy process. Patient Educ Couns 2008; 73(3): 418-25

[89] Fife CE, Benavides S, Carter MJ. A patient-centered approach to treatment of mprbid obesity and lower extremity complications: an overview and case studies. Ostomy Wound Manage 2008; 54(1): 24-32.

[90] Joosten EA, DeFuentes-Merillas L, de Weert GH, Senky T, van der Staak CP, de Jong CA. Systematic review of the effects of shared decision-making on patient satisfaction, treatment adherence and health status. Psychother Psychosom 2008; 77(4): 219-26.

[91] Rodriguez-Osorio CA, Dominguez-Cherit G. Medical decision making: paternalism vs patient center (autonomous) care. Curr Opin Crit Care 2008; 14(6): 708-13.

[92] Talley-Rostov A. Patient-centered care and refractive cataract surgery. Curr Opin Ophthalmol 2008; 19(1): 5-9.

[93] Birks YF, Watt IS. Emotional intelligence and patient-centered care. J R Soc Med 2007; 100(8): 368-74.

[94] Davidson I, Gallieni M, Saxena R, Dolmatch B. A patient centered decision making dialysis access algorithm. J Vasc Access 2007, 8(2): 59-68.

[95] Cooper-Patrick L, Gallo JJ, Gonzales JJ, et al. Race, gender and partnership in the patient-physician relationship. JAMA 1999; 282(6): 583-9.

[96] Doescher MP. Racial and ethnic disparities in perceptions of physician style and trust. Arch Fam Med 2000; 9(10): 1156-63.

[97] Kaplan SH, Gandek B, Greenfield S, et al. Patient and visit characteristics related to physicians' participatory decision-making style. Results from the medical outcomes study. Med Care 1995; 33: 1176-87.

[98] Saha S, Komaromy M, Koepsell TD, Bindman AB. Patientphysician racial concordance and the perceived quality and use of health care. Arch Intern Med 1999; 159: 997-1004.

[99] Beach MC. Can patient-centered attitudes reduce racial and ethnic disparities in care? Acad Med 2007; 82(2): 193.

[100] Cooper LA. Patient-centered communication, ratings of care, and concordance of patient and physician race. Ann Intern Med 2003; 139(11): 907.

[101] Safran DG, Taira DA, Rogers WH, et al. Linking primary care performance to outcomes of care. J Fam Pract 1998; 47: 213-20.

[102] Saha S. Patient-physician relationships and racial disparities in the quality of health care. Rev Panam Salud Publ 2003; 93(10): 1713.

[103] Schulman KA, Berlin JA, Harless W, et al. The effect of race and sex on physicians' recommendations for cardiac catheterization. $\mathrm{N}$ Engl J Med 1999; 340: 618-26.

[104] Thom DH, Ribisl KM, Stewart AL, et al. The Stanford trust study physicians. Further validation and reliability testing of the trust in physician scale. Med Care 1999; 37: 510-7.

[105] LaVeist TA, Nickerson KJ, Bowie JV. Attitudes about racism, Medical mistrust, and satisfaction with care among African American and White Cardiac patients. Med Care Res Rev 2000; 57(Suppl 1): 146-61

[106] Collins KS, Hughes DL, Doty MM, Ives BL, Edwards JN, Tenney K. Diverse communities, common concerns: assessing health care quality for minority Americans. Findings from The commonwealth fund 2001 health care quality survey. New York: The Commonwealth Fund 2002.

[107] Fiscella K. Patient trust: is it related to patient-centered behavior of primary care physicians? Med Care 2004; 42(11): 1049.

[108] Roter DL, Hall JA. Doctors talking to patients/patients talking to doctors: improving communication in medical visits. Westport, CT Auburn House 1992.

[109] Johnson RL. Patient race/ethnicity and quality of patient-physician communication during medical visits. Am J Publ Health 2004; 94(12): 2084.

[110] Koter DL, Stewart M, Putnam SM, Lipkin M Jr, Stiles W, Inui TS Communication patterns of primary care physicians. JAMA 1997; 277: 350-6.

[111] Ratanawongsa N, Zikmund-Fisher BJ, Couper MP, et al. Race, ethnicity, and shared decision making for hyperlipdemia and hypertension treatment: The DECISIONS survey. Med Dec Making 2010; 30: 65S-76S.

[112] Nazario RJ. Medical humanities as tools for the teaching of patientcentered care. J Hosp Med 2009; 4(8): 512-4.

[113] Quillin JM, Tracy K, Ancker JS, et al. Health care system approaches for cancer patient communication. J Health Commun 2009; 15(Supp 1): 85-94.

[114] Baker DW, Hayes R, Fortier JP. Interpreter use and satisfaction with interpersonal aspects of care for Spanish-speaking patients Med Care 1998; 36(10): 1461-70. 
[115] Carrasquillo O, Orav EJ, Brennan TA, Burstin HR. Impact of language barriers on patient satisfaction in an emergency department. J Gen Intern Med 1999; 14(2): 82-7.

[116] Crane JA. Patient comprehension of doctor-patient communication on discharge from the emergency department. Emerg Med J 1997; 15(1): 1-7.

[117] David RA, Rhee M. The impact of language as a barrier to effective health care in an underserved urban hispanic community. Mt Sinai J Med 1998; 65(5-6): 393-97.

[118] Derose KP, Baker DW. Limited English proficiency and latinos' use of physician services. Med Care Res Rev 2000; 57(1): 76-91.

[119] Enguidanos ER, Rosen P. Language as a factor affecting follow-up compliance from the emergency department. Emerg Med J 1997; 15(1): 9-12.

[120] Hornberger JC, Gibson CD Jr, Wood W, et al. Eliminating language barriers for non-English-speaking patients. Med Care 1996; 34(8): 845-56.

[121] Jacobs EA, Lauderdale DS, Meltzer D, et al. Impact of interpreter services on delivery of health care to limited-English-proficient patients. J Gen Intern Med 2001; 16(7): 468-74.

[122] Lee LJ, Batal HA, Maselli JH, Kutner JS. Effect of Spanish interpretation method on patient satisfaction in an urban walk-in clinic. J Gen Intern Med 2002; 17(8): 641-45.

[123] Seijo R, Gómez H, Freidenberg J. Language as a communication barrier in medical care for latino patients hispanic. J Behav Sci 1991; $13: 363$

[124] Stewart M, Brown BJ, Weston WW, McWhinney I, McWilliam CL, Freeman TL. Patient-centered medicine: transforming the clinical method. Thousand Oaks, CA: Sage 1995.

[125] Todd KH, Samaroo N, Hoffman JR. Ethnicity as a risk factor for inadequate emergency department analgesia. JAMA 1993; 269(12): 1537-9.

[126] Park ER, Betancourt JR, Kim MK, et al. Mixed messages: residents' experiences learning cross-cultural care. Acad Med 2005; 80(9): 874-80

[127] Weissman JS, Betancourt JR, Campbell EG, et al. Resident physicians' preparedness to provide cross-cultural care. JAMA 2005; 294(9): 1058-67.

[128] Suter E, Oelke ND, Adair CE, Armitage GD. Ten key principles for successful health systems integration. Healthc Q 2009; 13: 1623.
[129] Shields L, Pratt J, Davis LM, Hunter J. Family-centered care for children in hospital. Cochrane Database Syst Rev 2007; 1(CD004811).

[130] Kelleher S. Providing patient-centered care in an intesnive care unit. Nurs Stand 2006; 21(13): 35-40.

[131] Nazi KM, Hogan TP, Wagner TH, et al. Embracing health services research perspective on personal health records: lessons learned from the VA My HealthVet System. J Gen Intern Med 2010; 25(Suppl 1): 62-7.

[132] Cox Jl, Gray AJ. Psychiatry for the person. Curr Opin Psychiatry 2009; 22(6): 587-93.

[133] Maizes V, Rakel D, Niemiec C. Integrative medicine and patientcentered care. Explore: J Sci Healing 2009; 5(5): 277-89.

[134] Rynolds A. Patient-centered care. Radiol Technol 2009; 81(2): $133-47$.

[135] Galland L. Patient-centered care: antecedents, triggers, and mediators. Alternative Ther Health Med 2006; 12(4): 62-70.

[136] Irwin RS, Richardson ND. Patient-focused care: using the right tools. Chest 2006; 130(Suppl 1): S73-S82.

[137] Thistelthwaite J, Evans R, Tie RN, Heal C. Shared decision making and decision aids- a literature review. Aust Fam Physician 2006; 35(7): 537-40.

[138] Buffington DF. Future of medication therapy management services in delivering patient-centered care. Am J Health Syst Pharm 2007; 64(Suppl 10): S10-S12.

[139] Engel GL. The Need for a new medical model: a challenge for biomedicine. Science 1977; 196(4286): 8 .

[140] Kelly B, Zolnierek HMRD. Physician communication and patient adherence to treatment- a metal-analysis. Med Care 2009; 47(8): 826-34.

[141] Wolf D, Lehman L, Quinlin R, et al. Can nurses impact patient outcomes using a patient-centered care model? J Nurs Admin 2008; 38(12): 532-40.

[142] Yeheskel A, Aya B, Brokan JM. A course for teaching patientcentered medicine to family medicine residents. Acad Med 2000; 75(5): 494-7.

[143] Scherger JE. Future vision: is family medicine ready for patientdirected care? Fam Med 2009; 41(4): 285-8

(C) Jayadevappa and Chhatre; Licensee Bentham Open.

This is an open access article licensed under the terms of the Creative Commons Attribution Non-Commercial License (http://creativecommons.org/licenses/by$\mathrm{nc} / 3.0 /$ / / which permits unrestricted, non-commercial use, distribution and reproduction in any medium, provided the work is properly cited. 